\title{
Organised Surfactant System: Micro Emulsion
}

\author{
Mayur A Chordiya* \\ Department of Pharmaceutics, SNJBs SSDJ College of Pharmacy, India
}

Submission: March 30, 2017; Published: May 02, 2017

*Corresponding author: Mayur A Chordiya, Department of Pharmaceutics, SNJBs SSDJ College of Pharmacy, India; Tel: +91-9860975125

Email: chordiya.mayur@gmail.com

\section{Introduction}

The micro emulsion concept was introduced as early as 1940s by Hoar and Schulman who generated a clear single-phase solution by titrating a milky emulsion with hexanol. The term micro emulsion was first used by Jack H. Schulman, a professor of chemistry at Columbia University, in 1959. Alternative names for these systems are often used, such as transparent emulsion, swollen micelle, micellar solution, and solubilized oil. "Micro emulsions are dispersed, macroscopically homogeneous, thermo-dynamically stable, optically transparent, single-phase systems, formed by the spontaneous solubilisation of two otherwise immiscible liquids, in the presence of surfactants. In some cases, short-chain alcohols or amines are added to the mixture as co surfactants". The micro emulsion is formed by the intimate dispersion of one liquid in the other, as droplets [1].

\section{Advantages of micro emulsion based systems [2]}

a) Microemulsions are thermodynamically stable system and the stability allows self-emulsification of the system whose properties are not dependent on the process followed.

b) Microemulsions act as super solvents of drug.

c) The dispersed phase, lipophilic or hydrophilic (oilin-water, $\mathrm{O} / \mathrm{W}$, or water-in-oil, W/O microemulsions) can behave as a potential reservoir of lipophilic or hydrophilic drugs, respectively.

d) The mean diameter of droplets in microemulsions is below $0.22 \mu \mathrm{m}$; they can be sterilized by filtration.

e) Same microemulsions can carry both lipophilic and hydrophilic drugs.

f) Because of thermodynamic stability, microemulsions are easy to prepare and require no significant energy contribution during preparation. Microemulsions have low viscosity compared to other emulsions.

g) The use of microemulsion as delivery systems can improve the efficacy of a drug, allowing the total dose to be reduced and thus minimizing side effects. h) The formation of microemulsion is reversible. They may become unstable at low or high temperature but when the temperature returns to the stability range, the microemulsion reforms.

\section{Disadvantages of microemulsion based systems [3]}

a) Use of a large concentration of surfactant and cosurfactant necessary for stabilizing the nano droplets.

b) Limited solubilizing capacity for high-melting substances.

c) The surfactant must be nontoxic for using pharmaceutical applications.

d) Micro emulsion stability is influenced by environmental parameters such as temperature and $\mathrm{pH}$. These parameters change upon microemulsion delivery to patients.

\section{Structure \& dynamics of micro emulsion [4]}

Microemulsions are not static, impenetrable structures but very labile systems where rapid exchanges of individual components between the various environments as well as spontaneous fluctuation of the interfacial film occur continuously.

\section{Droplets phases}

0/W microemulsion: In the case of oil- in-water $(0 / W)$ microemulsions, droplets are formed with the surfactants head-groups oriented towards the continuous water phase and the nonpolar tails grouped inside the hydrophobic core of the aggregate.

W/0 microemulsion: In oil-rich microemulsions, water is solubilized as small droplets surrounded by a membrane of surfactant and co surfactant molecules. At high water concentration, microemulsions consist of small oil droplets dispersed in water, whereas at lower water concentrations the situation is reversed \& the system consists of water droplets dispersed in oil. In each phase the oil \& water are separated by surfactant-rich film. In general w/o systems can be prepared at higher disperse phase concentrations than $\mathrm{o} / \mathrm{w}$ systems, especially when ionic surfactants are used. The oil 
droplets in $\mathrm{o} / \mathrm{w}$ microemulsions are surrounded by the electric double layers, which can extended into the external phase for a considerable distance (up to $100 \mathrm{~nm}$ ), depending on the electrolyte concentration.

\section{Bicontinuous phases}

In many cases it is possible to effect a gradual transition from O/W to W/O microemulsion simply by changing the volume fraction of oil \& water. The intermediate region, which contains approximately equal volumes of oil \& water, is often composed of bi continuous structures where both the oil \& the water domains extend over macroscopic distances \& the surfactant forms an interface of rapidly fluctuating curvature, but in which the net curvature is near zero.

\section{Three important conditions for micro emulsion formulation [5]}

a. Surfactants must be carefully chosen so that an ultra low interfacial tension $(<10-3 \mathrm{mN} / \mathrm{m})$ can be attained at the oil / water interface which is a prime requirement to produce microemulsions.

b. Concentration of surfactant must be high enough to provide the number of surfactant molecules needed to stabilize the micro droplets to be produced by an ultra low interfacial tension.

c. The interface must be flexible or fluid enough to promote the formation of microemulsions.

\section{Micro emulsion preparation methods [5]}

The preparation of microemulsion requires the determination of existence region of microemulsions, which can be determined by visual observation of various mixtures of surfactant, co-surfactants, oily phase, and aqueous phase reported in phase diagram. There are two techniques for the preparation of microemulsion:

a. "Exact" process by auto-emulsification.

b. Process based on supply of energy (Homogenization).

Auto-emulsification: Due to spontaneous formation of microemulsions, they can prepare in step by mixing the constituents with reduced roughness. The order of the addition of constituents is not considered a critical factor for the preparation of microemulsion, but it can influence the time required to obtain equilibrium. This time will increase if the co surfactant is added to the organic phase, because its greater solubility in this phase will prevent the diffusion in the aqueous phase.

Process based on supply of energy: In this case microemulsions are not obtained spontaneously. A decrease of the quantity of surfactants results in the use of high pressure homogenizers in order to obtain the desire size of droplets that constitute the internal phase as opposed to the former technique.

\section{Release of drugs from microemulsions [6]}

The real partition of the drug between the aqueous \& the dispersed oil phase cannot be determined in microemulsion owing to the high stability of the system. So, it is not possible to determine the concentration of the drug in both phases directly. The release of drug from microemulsions is governed by two main processes,

a. Transfer of drug from the dispersed phase to the continuous phase.

b. Diffusion of the drug from the continuous phase.

\section{Microemulsions theory $[7,8]$}

a. The combination of emulsifying agents to give a mixed interfacial film \& their concentration must be such as to produce a meta stable negative free energy \& cause the adsorbed monolayer to spontaneously achieve zero interfacial tension. This causes the droplets to break up spontaneously ensuring that the system will remain dispersed \& will not, as microemulsions do, achieve equilibrium by separating into the original, mutually insoluble liquid phase's viz. phase separation.

b. The emulsifier interphone must not be too highly condensed; otherwise, the curvature necessary for very small droplets cannot be achieved.

c. To obtain this order i.e. fluidity in the condensed monolayer. It appear to be necessary for the molecules of the oil phase to interpenetrate or associate with the mixed interfacial film.

d. The negative free energy changes due to the adsorption of the surfactant \& Co-surfactant on the generated interface, plus the entropy of the dispersion of the droplets in the continuous phase, overcome the positive product of the small interfacial tension \& the large interfacial area.

e. The mixed interfacial film in equilibrium with both oil $\&$ water is liquid \& duplex in nature i.e. capable of possessing different tensions at each of its sides since the forces among the heads are different from those among the tails.

f. Thus in the flat film prior to curvature if the pressure at the oil side is greater than at the water side, the film will bond under the influence of the molecular forces at play, the pressure at the oil side is relieved so that after curvature, the pressure or tension at each side is same.

g. As the droplets become smaller, the interfacial area increases \& the emulsifier becomes depleted from the bulk phase by adsorption. Huge surface area accounts for large amounts of emulsifier required to form microemulsions.

\section{Stability of microemulsions [9]}

Microemulsions are stable with respect to separation into their components; macro emulsions may have a degree 
of kinetic stability but ultimately separates. Microemulsions formation and stability can be explained on the basis of a simplified thermodynamic rationalization. The free energy of microemulsion formation can be considered to depend on the extent to which surfactant lowers the surface tension of the oilwater interface and the change in entropy of the system such that,

$$
\mathrm{DG}_{\mathrm{f}}=\gamma \mathrm{DA}-\mathrm{TDS}
$$

Where,

$\mathrm{DG}_{\mathrm{f}}$ is the free energy of formation.

$\gamma$ is the surface tension of the oil-water interface.

DA is the change in interfacial area on micro emulsification.

DS is the change in entropy of the system which is effectively the dispersion entropy.

$\mathrm{T}$ is the temperature.

It should be noted that when a microemulsion is formed the change in DA is very large due to the large number of very small droplets formed. It is must however be recognized that while the value of $\gamma$ is positive at all times, it is very small (of the order of fractions of $\mathrm{mN} / \mathrm{m}$ ), and is offset by the entropic component.

The dominant favorable entropic contribution is the very large dispersion entropy arising from the mixing of one phase in the other in the form of large numbers of small droplets. However, favourable entropic contributions also arise from other dynamic processes such as surfactant diffusion in the interfacial layer and monomer-micelle surfactant exchange. Thus a negative free energy of formation is achieved when large reductions in surface tension are accompanied by significant favorable entropic change. In such cases, micro emulsification is spontaneous and the resulting dispersion is thermodynamically stable. Droplets do not coalesce due to surface free energy of microemulsion system. Interfacial tension of new droplet becomes negative, i.e. system has negative free surface energy. The larger droplet now spontaneously increases its curvature to effect zero interfacial tension.

\section{Acknowledgement}

The authors thank BCUD, Savitribai Phule Pune University, Pune for financial assistance.

\section{References}

1. Hung JG, Shou NC, Jenn SH, Tien C (1992) Studies of Formation and Interface of Oil/Water microemulsion. Chinese J Physics 30(5): 665.

2. Vyas SP, Khar RK (2002) Submicron emulsions in targeted and controlled drug delivery, Novel Carrier Systems. CBS Publishers and Distributors, New Delhi, India, pp. 282-302.

3. Shaji J, Reddy MS (2004) Microemulsions as drug delivery systems. Pharma Times 36(7): 17-24.

4. Eccleston GM (1994) In: Swarbrick J \& Boylan J (Eds.), Encyclopedia of pharmaceutical technology. Marcel Dekker Inc, USA, 9: 375-422.

5. Vandamme TF (2002) Microemulsions as ocular drug delivery systems: recent developments and future challenges. Prog Retin Eye Res 21(1): 15-34.

6. Sirotti C, Coceani N, Colomboc I, Lapasin R, Grassi M (2002) Modeling of drug release from microemulsions: a peculiar case. Journal of Membrane Science 204(1-2): 401-412.

7. Prince LM (1967) A theory of aqueous emulsion. I. Negative interfacial tension at the oil/water interface. J Colloid Interface Sci 23(2): 165173.

8. Overbeek J, Thi G (1978) Microemulsions, a field at the border between lyophobic and lyophilic colloids. Faraday Disc Chem Soc 65: 7-19.

9. Ktistis G, Niopas I (1998) A study on the in-vitro percutaneous absorption of propranolol from disperse systems. J Pharm Pharmacol 50(4): 413-418.

\section{Your next submission with Juniper Publishers} will reach you the below assets

- Quality Editorial service

- Swift Peer Review

- Reprints availability

- E-prints Service

- Manuscript Podcast for convenient understanding

- Global attainment for your research

- Manuscript accessibility in different formats

( Pdf, E-pub, Full Text, Audio)

- Unceasing customer service

Track the below URL for one-step submission

https://juniperpublishers.com/online-submission.php 